\title{
The Effectiveness of Playful Positive Psychology Interventions with Six Bricks and DUPLO® Play Box for Taiwan Children on Emotional Adaptation
}

\author{
Pay-Ling Harn, Shu-Hui Bo
}

\begin{abstract}
This study was aimed at using the playful approach of Six Bricks and DUPLO ${ }^{\circledR}$ Play Box to devolve playful positive psychology interventions for children. Subsequently, the application of this program, its emotional adaptation effect, and process of change were explored.Twenty-four fifth graderswere recruited as study participants. The participants were randomly allocated to an experimental group and control group.

The experimental group was invited to participate in the 3-hour playful positive psychology interventions. "Positive emotion scale for elementary students" and "elementary school students emotional competency scale" were used to conduct pretest and posttest for assessing the effects of the playful positive psychology interventions on the children's emotional adaptation. In addition, observations were recorded during the intervention process to examine the process of change and key events of change. The findings of this study were as follows: (a) positive emotions and emotional competence were significantly enhanced. (b) The process of change comprised the following stages: promotion of joy and concentration, and gender-based collaboration; cross gender-based collaboration and interpersonal containment; developing strengths and gratitude to deepen resilience; from building positive personal experiences to co-creating apositive collective memory; and extracting elements of happiness to build psychological capitals.
\end{abstract}

Index Terms-Playful approach, positive psychology interventions,emotional adaptation, Six Bricks, DUPLO ${ }^{\circledR}$ Play Box.

\section{INTRODUCTION}

The overall happiness index in recent years shows that more than $20 \%$ of children in Taiwan reported unsatisfactory happiness. The happiness index of Taiwanese children is below the global average and is dropping on a yearly basis[5], [6],[7].Therefore, how to improve children's positive emotion and promote emotional adaptation is very important. Why are children unhappy? Children's psychological stress stems primarily from family interactions, interpersonal relationships at school, and their physiological health[5]. A 2017 survey reported that children's happiness was most affected by their satisfaction with interpersonal relationships at school. Almost $40 \%$ of children believed that the key to happiness is making more friends [4]. A study asserted that psychological loneliness in children is related to social interactions and social networks [1]. Children's interpersonal

Pay-Ling Harn, Assistant Professor, Applied Psychology Department, Hsuan Chuang University, No.48, Hsuan Chuang Rd., Hsiang San District, Hsinchu City, Taiwan

Shu-Hui Bo,His Primary school teacher, Ruitang Elementary School, Taoyuan, Taiwan. networks are typically established at school; therefore, a friendly and supportive atmosphere among peers can facilitate enhancing children's positive emotions [7].

Fredrickson (2009) proposed the broaden-and-build theory of positive emotions to describe the importance of positive emotions[10]. The theory posits that positive emotions can extend the assets of an individual's instantaneous thinking actions and build their long-lasting personal resources. This will help individuals develop strategies to respond to changes in life. Positive emotions can eliminate the negative effects of negative emotions, a phenomenon called the undo hypothesis [9].

The theory of positive emotions is affected by positive psychology. Positive psychology is the scientific study of strengths aimed at promoting people's well-being. The concept of strengths is the cornerstone of positive psychology serving to help individuals to perceive life satisfaction and to feel that life has a meaning. Strength-based counseling is that applies the power of strengths to prompt change in a person. Another fundamental theory of positive psychology intervention is based on the well-being model of Seligman [15]. Works on positive psychology have been incorporated in children's education and counseling programs, such as strength-based parenting [16], and positive psychology education for children based on the PERMA (Positive emotions, Engagement, positive Relationships, Meaning, and Accomplishment) framework [15].

Previously, positive psychology exercises for children generally involve discussion or writing activities. Waters [16] integrated some games in strength-based parenting to inspire children's learning potential. "Play" is the key mechanism through which the positive emotion "joy" is elicited [10]. Children enter the concrete operational stage of development; thus, adopting the concrete, visual, operational, and practical mode can help children to internalize psychological capital. The Six Bricks and DUPLO® Play Box playful learning models have gained attraction in recent years and are applied in a wide range of counseling practices from early children's education to life adaptation. Related studies have demonstrated the functions of playful models in alleviating anxiety, promoting interpersonal collaboration, and building social connections [6],[7]. The Six Bricks and DUPLO® Play Box were developed by a group of South African teachers in hopes of encouraging children to develop important skills that enable them to become lifelong learners. These two types of playful learning models are based on a holistic approach that emphasizes the importance of physical, cognitive, creative, societal, and emotional skills and how these skills influence and complement each other. The characteristics of playful learning through the Six Bricks and DUPLO® Play Box are joyful, actively engaging, meaningful, iterative, and 


\section{The Effectiveness of Playful Positive Psychology Interventions with Six Bricks and DUPLO® Play Box for Taiwan Children on Emotional Adaptation}

socially interactive [17]. Joyful, actively engaging, meaningful, and socially interactive correspond directly to the four elements of the PERMA model [15], that is, positive emotions, engagement, relationship, and meaning. In addition, problem solving and knowledge transfer during the iterative process can lead to achievements. The Six Bricks and DUPLO® Play Box emphasize the importance of physical activity in learning. The area of the brain responsible for physical activity is the area participating in higher-level thinking. Physical activity stimulates the brain to learn and the entire body to collect information through the sensory system, thereby helping the brain to develop its neural network [17].

This study adopted the playful learning models of Six Bricks and DUPLO ${ }^{\circledR}$ Play Box (hereafter referred to as "SBPB") to identify, establish, and implement a playful counseling strategy, construct 3-hour playful positive psychology interventions, and explore their effects on emotional adaption. Based on discussions above, the objectives of this study were to elucidate (a) the effect of playful positive psychology interventions on children's emotional adaption; and (b) the changing process of children through playful positive psychology interventions.

\section{METHOD}

\section{A. Playful Positive Psychology Interventions with Six} Bricks and DUPLO® Play Box

Table 1. Playful positive psychology interventions

\begin{tabular}{ll}
\hline \multicolumn{1}{c}{ Topic } & \multicolumn{1}{c}{ Goal } \\
\hline Tricky Tower & $\begin{array}{l}\text { Improving physical skills } \\
\text { and joyful emotions. }\end{array}$ \\
emotional scale and & $\begin{array}{l}\text { Fostering Improving } \\
\text { Interpersonal collaboration, } \\
\text { problem solving, and } \\
\text { resilience, practicing } \\
\text { strengths. }\end{array}$ \\
Identifying strengths, \\
expressing gratitude, \\
savoring experience, and \\
fostering positive emotions. \\
Fostering Positive emotions, \\
positive interpersonal \\
relationship \\
Deepening positive \\
A happy train & emotions, interpersonal \\
& collaboration, positive \\
& empowerment.
\end{tabular}

For this study, the SBPB learning activities involving physical, cognitive, creative, social, and emotional skills were selected.Theplayful positive psychology interventions (hereafter referred to as "PPPI" )modifies the learning activities "Tricky Tower", "Bridge", "Good Friend", "Play Park" from SBPB.PPPI was integrated with positive psychology interventions strategies involving strength identification, building, and practice. PPPIserves to promote learning through joyful, meaningful, and actively engaging experiences and transform this process into deeper learning through iterative and socially interactive experiences. The program is ultimately used to promote children's emotion adaption and interpersonal development. Table 1 shows the playful positive psychology interventions.

\section{B. Participants}

Twenty-four fifth graders in elementary school aged 10 to 11 years, including 12 girls and 12 boys, were recruited as researchparticipants. The participants were randomly allocated to an experimental group $(n=12)$ and control group $(n=12)$. Twelve children of the experimental group were invited to participate in the 3-hour playful positive psychology interventions. The control group did not implement any treatment.

\section{Research Instruments}

(a) Positive emotion scale for elementary students. This study adopted the 28-item "positive emotion scale for elementary students" by Chuang \& Mao [8].This scale is a five-point Likert scale comprising four dimensions of joy (11 items), empathy (8 items), contentment (5 items), and self-confidence (4 items). If the score of the scale is higher, it means more positive emotions. The reliability analysis of this scale revealed an internal consistency (Cronbach's $\alpha$ ) of .923, indicating that the scale is reliable. Regarding validity analysis, the scale exhibited a total explained variation of $66 \%$ following factor analysis, indicating favorable validity.

(b) Elementary school student emotional competency scale. This study adopted the "Elementary school student emotional competency scale" by Chen [3] as the instrument for measuring emotionaladaption. The scale consists of 40 items in the dimensions of emotional expressive competence (11 items), emotional transformative competence (8 items), emotional managerial competence ( 8 items), emotional regulation competence ( 8 items), and emotional autonomy competence (5 items). A four-point Likert scale is adopted, with scores of 4 to 1 representing "always," "sometimes," "seldom," and "never," respectively.If the score is higher, it means stronger emotional competence.The reliability analysis of this scale revealed an internal consistency (Cronbach's $\alpha$ ) of .963 , indicating that the scale is reliable. Regarding validity analysis, the scale exhibited a total explained variation of $57.16 \%$ following factor analysis, indicating favorable validity.

(c) Records of observations. The entire process of PPPI was video-recorded, and the recordings were transcribed into transcripts to analyze the process of change.

\section{RESULT}

\section{A. The effectiveness of PPPI onemotionaladaptation.}

This study performed the t-test analysis to compare the score performance of the experimental group and control group in the "positive emotion scale for elementary students" and "elementary school student emotional competency scale" before and after the interventions. Table 2 shows that the experimental and control groups have no significant difference in the pretest on each dimension of the "positive emotion scale for elementary students" and "elementary school student emotional competency scale". This indicates that there was no significant difference in the scores between the two groups before the interventions were involved.However, Table 3indicates that the experimental and control groups showed significant difference in the protest on each dimension of the "positive emotion scale for elementary students" and "elementary school student emotional competency scale". This result reveals that PPPI significantly enhances the children's positive emotions and emotional competency. 
Table2.Independent sample t-test analysis on pretest score

\begin{tabular}{lcccccc}
\hline & \multicolumn{2}{c}{$\begin{array}{c}\text { Experimental } \\
\text { group }\end{array}$} & \multicolumn{2}{c}{$\begin{array}{c}\text { Control } \\
\text { group }\end{array}$} & $t$ & $p$ \\
& $\mathrm{M}$ & $\mathrm{SD}$ & $\mathrm{M}$ & $\mathrm{SD}$ & & \\
\hline joy & 43.5 & 6.43 & 34.33 & 8.02 & 3.09 & .513 \\
empathy & 32.0 & 6.28 & 25.58 & 6.63 & 2.43 & .960 \\
contentment & 21.5 & 4.44 & 17.42 & 3.55 & 2.49 & .500 \\
self-confidence & 17.67 & 3.20 & 13.42 & 4.19 & 2.79 & .280 \\
\hline expressive & 36.83 & 3.49 & 28.00 & 5.72 & 4.57 & .073 \\
transformation & 26.42 & 4.38 & 20.58 & 4.23 & 3.32 & .470 \\
management & 25.58 & 3.15 & 19.33 & 4.50 & 3.94 & .550 \\
regulation & 27.08 & 3.06 & 18.50 & 4.46 & 5.50 & .240 \\
autonomy & 16.75 & 2.56 & 13.17 & 2.79 & 3.28 & .240 \\
\hline
\end{tabular}

Table3.Independent sample t-test analysis on protest score

\begin{tabular}{lcccccc}
\hline & \multicolumn{2}{c}{$\begin{array}{c}\text { Experimental } \\
\text { group }\end{array}$} & \multicolumn{2}{c}{ Control } & $t$ & $p$ \\
& $\mathrm{M}$ & \multicolumn{1}{c}{ SD } & \multicolumn{1}{c}{ M } & \multicolumn{1}{c}{ SD } & & \\
\hline joy & 49.25 & 1.6 & 36.83 & 11.90 & $3.58^{*}$ & .002 \\
empathy & 35.67 & 2.10 & 26.83 & 8.01 & $3.70^{*}$ & .010 \\
contentment & 22.92 & 1.38 & 18.75 & 5.56 & $2.52^{*}$ & .003 \\
self-confidence & 18.5 & 1.31 & 12.58 & 4.60 & $4.28^{*}$ & .003 \\
\hline expressive & 37.92 & 1.62 & 31.00 & 7.92 & $2.96^{*}$ & .001 \\
transformation & 26.33 & 3.47 & 6.84 & 21.92 & $1.99^{*}$ & .035 \\
management & 27.42 & 2.11 & 22.33 & 5.71 & $2.89^{*}$ & .001 \\
regulation & 27.08 & 2.54 & 22.75 & 7.25 & $1.95^{*}$ & .001 \\
autonomy & 17.25 & 2.09 & 14.17 & 4.28 & $2.24^{*}$ & .004 \\
\hline \multicolumn{2}{c}{ Note: ${ }^{*} p<.05$} & & & & &
\end{tabular}

\section{B. Changing process throughPPPI}

Through the PPPI history record analysis, the changing process of intervention change can be divided into the following five stages:

(a) Promotion of joy and concentration, and gender-based collaboration. The psychosocial characteristics of the fifth graders in primary school are the gender grouping and implicit emotional expression [11]. In this study, the first author served as a counselor. First, the counselor used the physical activities and collaborative tasks, such as "Tricky Tower" and "Bridge", to increase engagement and joyful emotions. During the interventions, the children delivered nonlinguistic messages, such as joyful emotions through smiling. The children collaborated independently with each other to accomplish joint goals. At this point, children were found to be more physically interactive, although they still preferred a gender-based collaboration mode (Figure 1).

(b) Crossgender-basedcollaboration and interpersonal containment. When building an emotional scale together, the group of girls kept failing to complete the emotional scale. Subsequently, the counselor invited the girls to join the boys' group. Attributed to the positive emotions from earlier activities, the boys and girls were willing to cross the gender barrier and collaborate with each other. The cross gender-based collaborative behaviors are presented. One of the girls placed her emotional figure on the emotional scale, instantly causing the scale to collapse. The counselor said to everyone in a contained manner. At this time, a boy stepped forward and volunteered to repair the emotional scale. He comforted the girl, saying "don't worry, I'll fix the bridge." Instant face failure of the task, none of the children pointed fingers to blame one another. This behavior manifests a form of interpersonal containment. Finally, the girls and boys completed building the emotional scale and placing their emotional figures together (Figure 2).

(c) Developing strengths and gratitude to deepen resilience. Children belong to the concrete operational stage, mainly through the concrete life experience to form an understanding of the world [11]. Therefore, the concrete, operational, and practical activities in the SBPB can facilitate children's mental development. By having the children work together in building emotional figures and emotional scale, the counselor lead children to identify and develop advantages from the substantive experience of co-creation.Subsequently, the children engaged in the Play Box activities to build their gratitude journals, explore the strengths they displayed as they complete a task together, learn the strengths of others, and develop a sense of gratitude. The girl, who caused the emotional scale to collapse, attached a note to her strength figure (Figure 3) that says "Iam happy, because I was able to complete a task through teamwork." Even in the face of failure, the girl can still see her own strength in the failed task is "Love learning". She also appreciate the strength "leadership "of the boy who stood up to repair the emotional scale and express gratitude to the boy.As indicated by Waters [11], witnessing one's own strengths in adversity is conducive to fostering children's resilience.

(d) From building positive personal experiences to co-creating a beautiful collective memory. The counselor expands the positive experiences of this moment to include positive interpersonal experiences at school. The counselor invited all the children to build the positive experiences in school through DUPLO® Play Box. Subsequently, through collective co-creation of positive experiences, all the models were integrated. The children began building whatever they wanted through harmonious teamwork. They collectively named the model "A happy elementary school". A key event at this stage is as indicated on the top right of Figure 4, which is a symbolic model showing a group of children gathered around a table to learn together and keep each other company. All the children believed that this is the happiest moment at school. From a gender grouping in the beginning to the subsequent collaborative playful learning, all of the children jointly created a "happy elementary school" in their minds, as demonstrated by the model in which all the children gathered around a table to learn together through play. This scene reflects the psychological and behavioral changes in the research participants.

(e)Extracting elements of happiness to build psychological capitals. In presenting the positive experiences of completing the happy school model, the children were invited to build elements of happiness and a happy train compartment with DUPLO ${ }^{\circledR}$ Play Box. The purpose of this activity was to help the children to conceptualize specific terms of happiness and deepen their positive experiences. Finally, the children's train compartments were connected, forming a happy train. This activity further deepens the children's positive psychological image of interpersonal connections and increases children's physical activity through pushing of the train. Physical activity is crucial to learning because it stimulates the brain to learn, prompting the entire body to collect information through the sensory system [17]. 

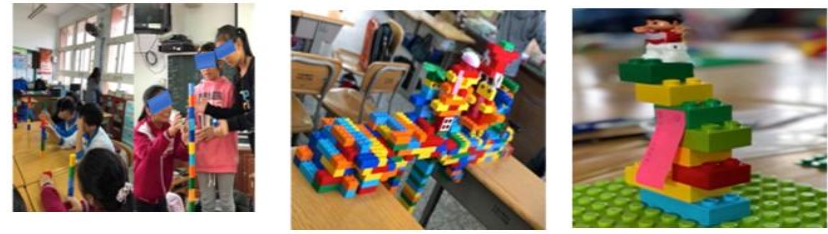

Figure1.Tricky tower Figure2.Emotion scale Figure3.Gratitude journal
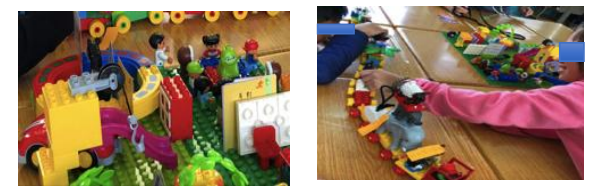

Figure4.A happy time

Figure5.A happy train

\section{COUNCLUSION}

This study adopted the SBPB to develop playful positive psychology interventions for children, which was used to explore the effectiveness on children's emotion adaption and interpersonal development. According to the study results, PPPI significantly enhance children's positive emotions and emotional competence. Joyful emotions are the core of playful learning models [17]. This result echoes Fredrickson'sbroaden-and-build theory of positive emotions[9]. Joyful emotions facilitate emotion regulation. Throughout the entire intervention process, children were observed to switch from a gender-based interactive model to a cross gender-based cooperation model. The children connected this successful experience to the positive experiences at school; they extracted elements of happiness and built and leveraged their strengths. All of these actions elicited a change in children's interpersonal development and emotion adaption, suggesting that the children's positive emotions definitely serve to build their cognitive and social resources.

PPPI of this study was based on the characteristics of children's cognitive, emotional, and interpersonal development. It not only offers a wide range of counseling activities that promote cognitive, creative, physical, social, and emotional experiences, but it also fully utilizes the concept of a holistic approach to playful learning. In the process, several key mechanisms through which playful experiences lead to changes in children were observed; for example, the children expressed joyful emotions; they were fully engaged; they found the meaning of using their strengths to complete tasks; they underwent an iterative process of learning new solutions from failure; and they improved their social skills [11],[17]. This result also resonates with the five elements of Seligman's PERMA framework (i.e., positive emotions, engagement, positive relationships, meaning, and accomplishment)[15].

According to the study results, the playful positive psychology interventions can build children's psychological capital (e.g., optimism, resilience, and self-efficacy). This result is consistent with previous studies, which indicated that playful approach interventions reduce negative emotions and build social resources [12],[13]. Therefore, this research finding can serve as a reference for positive psychology interventions and academic research. However, this study's program was designed to last 3-hour, and its delayed effect could not be evaluated. This limitation affects the applicability of the program and the generalizability of the research results. Future studies could extend the duration of the program and introduce additional topics to further expand its change effects.

\section{REFERENCES}

[1] Asher, S. R., Hymel, S., \& Renshaw, P. D. (1984). Loneliness in children. Child Development, 55, 1456-1464.

[2] Braun, V., \& Clarke, V. (2006). Using Thematic Analysis in Psychology. Qualitative Research in Psychology, 3 (2), 77-101.

[3] Chen, C.Y. (2012). Research on the survey and the counseling effects of children's emotional disturbance.(Unpublished master dissertation). Tanana University, Tanana.

[4] Child Welfare League Foundation (2017). 2017 Survey of children's well-being. Retrieved November 6, 2019, from https://www.children.org.tw/research/detail/67/1019

[5] Child Welfare League Foundation (2018a). An analysis report on the annoyances of children and adolescents and parental rearing attitudes in 2018.Retrieved November 6, 2019, fromhttps://www.children.org.tw/research/detail/72/1408

[6] Child Welfare League Foundation (2018b). Survey of children's well-being. Retrieved November 6, 2019, fromhttps://www.children.org.tw/research/detail/67/1353

[7] Child Welfare League Foundation ( 2019 ) 。 2019 Interpersonal relationship survey report on children and adolescents in Taiwan. Retrieved November 6, 2019, fromhttps://www.children.org.tw/research/detail/70/1491

[8] Chuang, Y.J., \& Mao, K.N., (2006). The construction of an " affective education" curriculum for fourth-grade Taiwanese students. Journal of Taiwan Normal University: Education, 51(2),121-146.

[9] Fredrickson, B.L., \& Levenson, R.W. (1998). Positive emotions speed recovery from the cardiovascular sequel of negative emotions. Cognition and Emotion, 12,191-220.

[10] Fredrickson, B. L. (2009). Positivity. New York: Three rivers press.

[11] Kail, R.V., \& Cavanaugh, J. C.(2016).Human development: A life-span view. Singapore: Cengage Learning

[12] Harn, P. L., \& Hsiao, C.C. (2018a). A Preliminary Study on LEGO®-Based Workplace Stress Reduction with Six Bricks and LEGO® SERIOUS PLAY® in Taiwan. World Journal of Research and Review, 6(1), 64-67.

[13] Harn, P. L., \& Hsiao, C.C. (2018b). Strenghth-4D career model with LEGO ${ }^{\circledR}$ Serious Play and Six Bricks. International Journal of Management and Applied Research, 5 (4), 157-172. doi: 10.18646/2056.54.18-012

[14] Norrish, J. M. (2015). Positive education: The Geelong grammar school journey. UK: Oxford University Press.

[15] Seligman, M.E.P. (2011). Flouring: A new understanding of happiness and wellbeing. New York, NY: Nicholas Berkley Publishing.

[16] Waters, L. (2017). The strength switch: How the new Science of Strength-Based. parenting can help your child and your teen to flourish. New York: Avery.

[17] Zosh, J.M., Hopkins, E. J., Jensen, H., Liu, C., Neale, D., Hirsh-Pasek, K., Solis L.S., \& Whitebread, D. (2017). Learning through play: a review of the evidence.Demark: LEGO Foundation.

Pay-Ling Harn received Ph.D. degree in educational psychology and counseling from Taiwan Normal University, Taipei, Taiwan. Currently, she is an assistant professor at Hsuan Chuang University, Hsinchu, Taiwan. She is certified counseling psychologist, Six Bricks and Play Box master trainer. Her research interests are in positive psychology, career counseling, and playful positive psychology interventions.

Shu-Hui Bo received Master degree in applied psychology from Hsuan Chuang University University, Hsuan, Taiwan. Currently, she is an primary school teacher at Ruitang Elementary School, Taoyuan, Taiwan. 